\title{
Distal radyoulnar eklem artritinde eklem protezleri
}

\author{
Implant arthroplasty for the distal radioulnar joint arthritis
}

\author{
Yalın Dirik, Feridun Yumrukçal, Mehmet Alp
}

Memorial Şişli Hastanesi, Ortopedi ve Travmatoloji Kliniği, İstanbul

\begin{abstract}
Son yıllarda; distal radyoulnar eklemin (DRUE) anatomik ve biyomekanik öneminin daha iyi anlaşılmaya başlanması, uygulanacak cerrahi tedavilerin seçimini de daha önemli bir duruma getirmiştir. Osteoartrit, romatoid artrit veya travma sonrası artrit gibi sebeplere bağlı olarak gelişen distal radyoulnar eklem problemleri; geleneksel olarak çeşitli rezeksiyon artroplastisi yöntemleriyle tedavi edilebilmektedir. Bu tür tedaviler hastanın ağrısını hafifletmekle beraber normal eklem anatomisini restore etmediklerinden distal radyoulnar eklemin yük transferini ve kinematiğini tesis edemezler. Parsiyel, total hemiartroplasti veya total DRUE protezlerinin kullanım amacı; stabil ve ağrısız, fonksiyonel ön kol rotasyon arkını restore etmektir. Tümöre bağlı distal ulna rezeksiyonunun gerektiği durumlar veya akut travmaya bağlı kötü kemik kalitesi olan hastaların çok parçalı ulna başı ve boyun kırıklarında da, daha nadir olarak protez uygulaması gerekebilir. Parsiyel DRUE protezlerinin erken dönemde klinik olarak iyileşmeye yardımcı olduğu bilinse de uzun dönem sonuçlarının çok iyi bilinmemesi hasta seçimi konusunda çok dikkatli olunması gerektiğini göstermektedir.
\end{abstract}

Anahtar sözcükler: distal radyoulnar eklem; artrit; implant artroplastisi

\begin{abstract}
In recent years; better understanding of the anatomical and biomechanical importance of the distal radioulnar joint (DRUJ) has made the selection of surgical treatments to be applied more important. Distal radioulnar joint problems due to osteoarthritis, rheumatoid arthritis or post-traumatic arthritis can traditionally be treated with various resection arthroplasty methods. Although such treatments alleviate the patient's pain, they do not establish the load transfer properties and kinematics of the distal radioulnar joint as they do not restore the proper anatomy. Partial hemiarthroplasty, total hemiarthroplasty or total DRUJ prostheses aim to restore the stable and painless functional forearm rotation arc. In cases where distal ulna resection is required due to tumor or for the patients with poor bone quality suffering comminuted fractures of the ulnar head and neck, prosthetic replacement may also be indicated. Although clinical improvement is achieved with partial DRUJ prostheses in early follow-ups, the long-term results being not well known dictates a careful patient selection
\end{abstract}

Key words: distal radioulnar joint; arthritis; implant arthroplasty

hastaların çok parçalı ulna başı ve boyun kırıklarında $\mathrm{da}$, daha nadir olarak protez uygulama endikasyonları vardır. Aktif enfeksiyon varlığı, açık yara olması ve yetersiz ulnar kemik stoğu kesin kontrendikasyonlarıdır. Şiddetli bağ instabilitesi, enfeksiyon hikâyesinin varlığı ve implant stabilitesini sağlayacak yeterli yumuşak dokunun olmaması relatif kontrendikasyonlarıdır. Radius ve ulnada yanlış kaynama (malunion) mevcutsa protez öncesinde veya eş zamanlı olarak bu deformitenin düzeltilmesi önerilir. Essex-Lopresti tipinde kalıcı radyoulnar instabilite durumlarında protez uygulamasından kaçınılmalıdır. ${ }^{[1]}$

- Illetişim adresi: Prof. Dr. Mehmet Alp, Memorial Şişli Hastanesi, Piyalepaşa Bulvarı 34385 Şişli, İstanbul

Tel: 0533 - 3183387 e-posta: alpmehmet@gmail.com

- Geliș tarihi: 30 Mayıs $2021 \quad$ Kabul tarihi: 9 Haziran 2021

ORCID iD: Yalın Dirik, 0000-0002-7510-0335 • Feridun Yumrukçal, 0000-0002-5714-7324 • Mehmet Alp, 0000-0002-6737-6526 


\section{PARSIYEL HEMIARTROPLASTI}

Ulna başının hasarlanmış eklem yüzeyinin protez ile rekonstrüksiyonudur. Kemik rezeksiyonunun az olması, ekstansör karpi ulnaris (EKU) ve distal ulna stabilizatörlerinin korunabilmesi ve triangular fibrokartilaj kompleks (TFKK) insersiyosunun detaşe edilmeden protezin uygulanabilmesi avantajlarıdır. ${ }^{[2]}$ Kopylov, 2007 yılında tek parçadan oluşan metalik implantın (First Choice DRUJ system, Integra - Ascension Orthopedics, Inc., Austin, TX, USA) erken dönem sonuçlarını bildirmiştir (Şekil 1). ${ }^{[3]}$ Garcia-Elias, medüller kanala yerleştirilen titanyum stem ve hemisferik pirokarbondan oluşan (Eclypse, Tornier, Bioprofile, Grenoble, France) protezin erken dönem sonuçlarını yayımlamıştır. İki ayrı komponenten oluşan bu protez proksimaldistal translasyona ve hafif aksiyel rotasyona izin vermektedir (Şekil 2). ${ }^{[4]}$

\section{TOTAL HEMIARTROPLASTI}

Ulna başının tamamının veya sigmoid çentiğin (notch) eksize edildiği durumlarda uygulanır. Swanson, 1968 yılında ısı ile kalıplanmış silikon protezi (Silastic, DOW Corning, Midland, MI, USA) tanıtmıştır. ${ }^{[5]}$ Altı değişik boyda olan ulnar stemi mevcuttur. Ulna distal rezeksiyon bölgesinde neredeyse $1 \mathrm{~cm}$ 'ye yakın kemik rezorpsiyonları görülmesi sonucunda gevşeme, stem kırıkları, çıkık ve sinovit gibi komplikasyonların sık görülmesi nedeniyle kullanımı bırakılmıştır.

Van Schoonhoven, 1998 yilında UHP Herbert ulnar head prosthesis (KLS Martin Group, Tuttlingen, Germany) isimle anılan rijit implantı geliştirmiştir. İki komponentten oluşur. Press-fit yerleşen konik titanyum stem, üç ayrı boy yakalıktan oluşur ve yine üç ayrı boy seramik baş şeçeneği vardır. Kapsüler rekonstrüksiyon imkânı olsa da majör instabilite durumlarında önerilmemektedir. Herbert ve van Schoonhoven, 2007 yılında bu protezin uzun dönem sonuçlarını bildirmişlerdir (Şekil 3). ${ }^{[6]}$

Mayo Klinik'ten Berger ve Cooney, benzer tipte modüler protezi (uHead, Avanta Orthopaedics Inc., San Diego. CA, USA) geliş̧tirmişlerdir. Titanyum püskürtme kaplamalı kobalt kromdan stem, iki ayrı boyda boyun seçeneğine sahiptir. Baş kısmı semisferik kobalt krom alaşımdan oluşur ve üzerindeki iki delik yumuşak doku stabilizasyonu için kullanılabilir. ${ }^{[7]}$

Kobalt krom ulna başı ve titanyum stemden oluşan benzer bir implantın ise diğerlerinden farklı olarak baş yapısı eksantriktir $\left(1,5^{\circ}-3^{\circ}\right.$ offset) ve yüzeyi yumuşak doku ataşmanı için pürüzlü yapılmıştır (E-Centrix, Wright Medical Technology, Inc., Arlington, TN, USA).. ${ }^{[2]}$

Radyal sigmoid çentik (notch) hemiartroplastisi; ulna başı protezlerinin stabilitesini artırmak için tasarlanmıştır. Stability sigmoid notch (Small Bone Innovations,

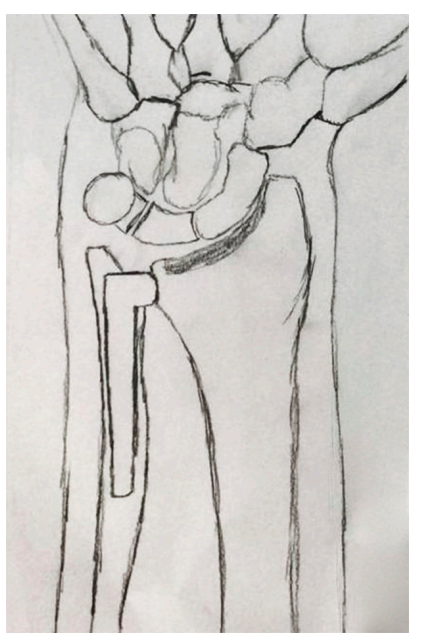

Şekil 1. Parsiyel hemiartroplasti (First Choice DRUJ system, Integra - Ascension Orthopedics, Inc., Austin, TX, USA).

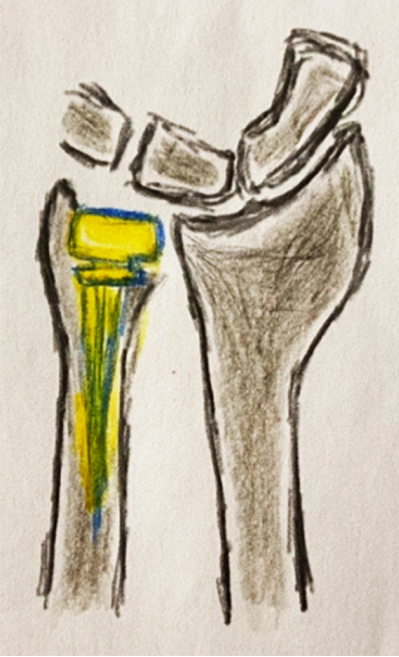

Şekil 2. Parsiyel hemiartroplasti (Eclypse, Tornier, Bioprofile, Grenoble, France).
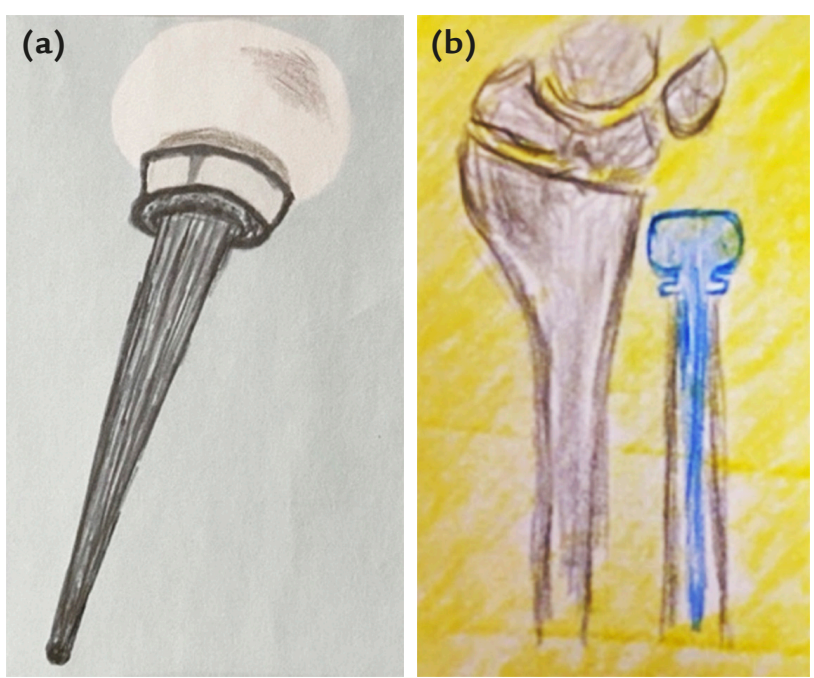

Şekil 3. a, b. Total hemiartroplasti (UHP Herbert ulnar head prosthesis) (KLS Martin Group, Tuttlingen, Germany). 


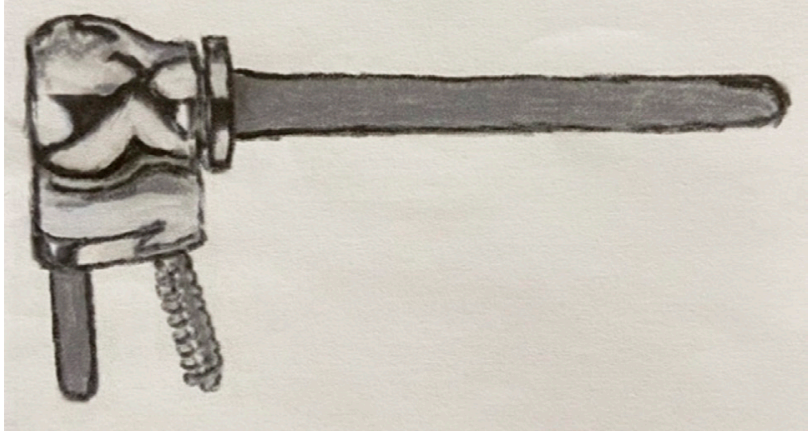

Şekil 4. Radyal sigmoid çentik (notch) hemiartroplastisi: stability sigmoid notch (Small Bone Innovations, Morrisville, PA, USA).

Morrisville, PA, USA) adl, iki komponentten oluşan bu modüler implant; plazma spray titanyum kaplamalı kobalt krom radyal plağa adapte edilmiş ultra high moleculer weight (UHMW) polietilen insert'ten oluşur. Bu plak radiusa bir adet distal peg ve bir adet kobalt krom vida ile tespit edilir. Ulna başı protezlerinin sebep olduğu sigmoid çentiğin aşınmalarına bağlı ağrının tedavisinde önerilmektedir (Şekil 4). ${ }^{[2]}$

\section{Cerrahi Teknik}

Ameliyat öncesinde çekilen grafilerde şablon ile protezin baş büyüklüğü ve stem kalınlığı ölçülmesinde ve rezeksiyon seviyesinin belirlenmesinde yarar vardır. Hasta supin pozisyonda iken, ön kol pronasyonda durur ve cerrahi işlem turnike altında gerçekleştirilir. Beşinci kompartman üzerinden dorsal uzunlamasına kesi yapılır. Ulnar sinirin dorsal duyusal dalı bulunarak korumaya alınır. Beşinci ekstansör kompartmanın üzerinden ekstansör retinakulum uzunlamasına kesilir ve ekstansör dijiti minimi tendonu radyal tarafa ekarte edilir. Böylece DRUE dorsal kapsülü ortaya koyulmuş olur. Ardından kapsül $L$ şeklinde keskin disseksiyon ile kesilir. Distal radius yapışma yerindeki kapsül kılıfı sonrasında tamire olanak vermesi için sağlam bırakılır. Kapsül proksimalde ulna cisminden (şaftından) distale doğru serbestleştirilir ve subperiostal disseksiyon ile ulna başı ortaya konur. Ekstansör karpi ulnaris tendonun salim oluğu ve kıllfının içinde olduğundan emin olunmalıdır. Triangular fibrokartilaj değerlendirilir. Herhangi bir yırtık veya defekt mevcutsa ve ihtiyaç varsa onarılmalıdır.

Ulna başı ekartörler yardımı ile dorsale doğru kaldırıldıktan sonra, ameliyat öncesinde planlandığı şekilde ve ameliyat esnasında kesi kılavuzuna göre uygun seviyeden cisme dik olacak şekilde osteotomize edilir ve eksize edilir. Ardından sigmoid çentik değerlendirilir; varsa osteofit, debris veya skar dokuları eksize edilir ve gerekirse burr ile derinleştirilebilir. Sonrasında ulna medullası, protez press-fit yerleşecek şekilde uygun boya kadar oyulur.

Deneme stem ve baş yerleştirildikten sonra ulnar komponentin sigmoid çentik içindeki yüksekliği değerlendirilir. Ulnar varyans, stem yerleşimi ve baş büyüklüğü skopi ile kontrol edilir. Ulnar varyansın nötral ile 1-2 mm negatif ulnar varyans arasında olması önerilir. Ön kol rotasyonu, ulna başı stabilitesi ve tracking değerlendirilir. Redüksiyon stabil olmalı ve pronasyon-supinasyon tam olmalıdır. Herşey uygunsa deneme protezler çıkartılır ve gerçek implantlar yerleştirilir. İmplantlar yerleştirilmeden önce kapama için TFKK emilmeyen sütür materyalleri ile tespit edilir ve komponetler yerleştirildikten sonra TFKK distal ulnar steme veya varsa protezin baş kısmındaki deliklere sütüre edilir. Ardından dorsal kapsül onarılır. Yumuşak doku örtümü protez stabilitesini koruyacak sıkılıkta olmalıdır ama tam pronasyon ve supinasyon hareketine de izin vermelidir. ${ }^{[1,6]}$

Parsiyel ulnar artroplasti uygulamasında ise farklı olarak ulnar stiloide yapışan yumuşak doku yapışma yerleri sağlam bırakılır. Eclypse ${ }^{\circledR}$ pyrocarbon spacer uygulamasında, TFKK'nin foveal yapışma kısmının kesilmesine gerek kalmadan implant yerleştirilebilir. The First Choice DRUJ System olarak anılan protez uygulamasında ise foveal yapışma yeri gevşetilir.

\section{Rehabilitasyon}

İlk üç hafta ön kol supinasyon pozisyonunda atelde tutulur. Sonraki üç haftada atele devam edilir ama aktif pronasyon hareketlerine başlanır. Altıncı haftada pasif germe ve sekizinci haftada güçlendirme egzersizlerine başlanır.

\section{Komplikasyonlar}

Enfeksiyon, EKU tendiniti, geçmeyen ağrı, dorsal ulnar duyusal sinir yaralanması, kompleks bölgesel ağrı sendromu, eklemde katılık ve instabilite sık olmasa da görülebilen komplikasyonlardır. Uygun protez baş büyüklüğü seçimi ve yeterli yumuşak doku tamirine özen göstermek gibi dikkatli cerrahi uygulamalar ve uygun rehabilitasyon ile komplikasyon gelişme riski azaltılabilir. Romatoid artrit veya radyal deformite gibi hastaya bağlı olan bazı faktörler ise komplikasyon riskini artırabilir. Eğer komponent ulnar pozitif varyansta uygulanmışsa ya da rezeksiyon çok distalden yapılmışsa veya protez çok büyükse ulnar impaksiyona sebep olabilir. Olması gerektiğinden büyük baş uygulamaktan kaçınılmalıdır. Medulla fazla oyulursa veya stem ince olursa gevşeme ve kırık riski olabilir. ${ }^{[6]}$ 


\section{TOTAL DRUE IMPLANT ARTROPLASTISi}

Scheker, 2000 yilında constrained ball and socket total implant artroplastisi uygulamalarını yayımlamıştır (APTIS Medical, Louisville, KY, USA). Ulnar stem önceleri paslanmaz çelikten yapılmış, sonrasında dayanıklılığı artırmak için kobalt krom ile değiştirilmiştir. Stemin distalindeki peg'e adapte olan küre, pronasyon-supinasyon esnasında proksimal-distal migrasyona izin verir. Küre, UHMW polietilenden yapılmıştır ve üç ayrı boyu vardır. Radyal komponent plaktan oluşur ve sigmoid çentik seviyesinden bir adet peg ve onun proksimal seviyesinden beş adet vida ile radiusa adapte edilir. Plağın distalinde küre ile birleşen soket mevcuttur (Şekil 5). ${ }^{[8]}$

Schuurmann ve Teunis, son dönemde hidroksiapatit kaplı iki parçadan oluşan yeni bir protez tasarımının gelişimini bildirmişlerdir. Erken sonuçlar cesaret verici olmakla beraber bazı ilk tasarımlar yüksek komplikasyon sayılarına sahiptir (Şekil 6). ${ }^{[9]}$

\section{Endikasyonlar}

Başarısız olmuş Darrach, Bowers, Watson veya Sauvé-Kapandji ameliyatları sonrasında kurtarıcı olarak veya ulnanın geniş eksizyonlarını gerektiren (tümör, Madelung's deformitesi, Ehler-Danlos sendromu gibi) durumlarda total DRUE protezi uygulanabilir. Unipolar ulna başı protez uygulamalarının başarısız sonuçlarının tedavisinde ve implant-kemik arayüzündeki gevşemelerde veya karşı eklem yüzeyinde oluşan bozulmaların tedavisinde de kullanılabilir.

\section{Kontrendikasyonlar}

İmmatür kemiklerde, ileri derece osteoporoz durumlarında, metal alerjisi olanlarda (özellikle nikele karşı), aktif enfeksiyon veya osteomiyelit varlığında ve kalan proksimal ulna $11 \mathrm{~cm}$ 'den kısa ise kontrendikedir. ${ }^{[8]}$

\section{Cerrahi Teknik}

Distal ulnanın dorsolateralinden (EKU ve ekstansör dijiti minimi tendonları arasındaki aralıktan) yaklaşık 8-9 cm distale doğru uzatılan kesi; ulna başı seviyesinde yaklaşık $2 \mathrm{~cm}$ radyal tarafa doğru uzatılır ve böylece hokey sopası şeklinde cerrahi kesi tamamlanır. Ardından $4 \times 4 \mathrm{~cm}$ 'lik, tabanı ulnar tarafta olacak şekilde ve ekstansör retinakulumun $3 \mathrm{~mm}$ proksimalinden, dorsal fasya flebi oluşturulur. Bu flep, sonraki aşamalarda EKU ve protez arasında tampon görevi görmek ve protezin ulnar yüzeyini kaplamak için kullanılacaktır. Illerleyen yıllarda ulna distalinden ektopik kemik oluşumunu engellemek için ulna başı, çevresindeki periostal kılıf ile beraber eksize edilir. Radyal deneme plağ yerleştirilir ve bu aşamada gerekirse sigmoid çentiğin volar dudağı eksize edilerek plak tam adapte edilir ve

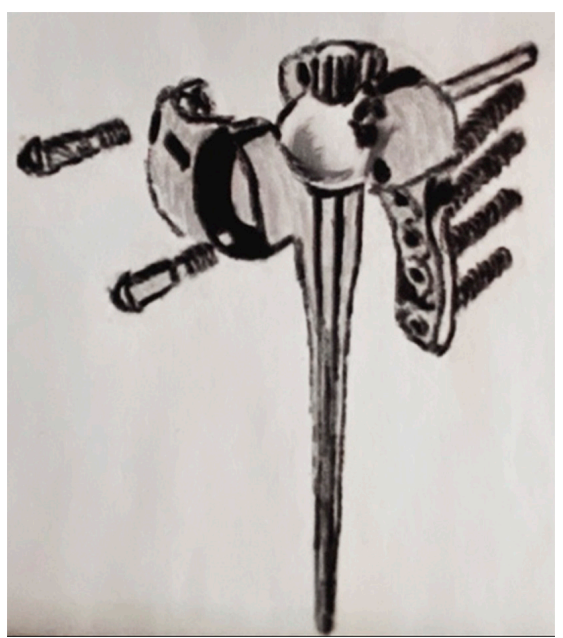

Şekil 5. Aptis DRUJ total protezi.

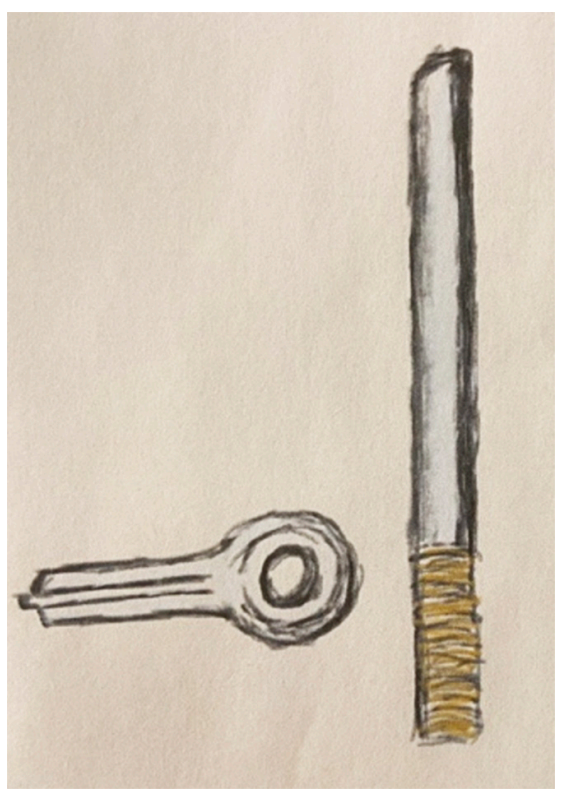

Şekil 6. Shuurmann, Teunis total protezi.

iki adet Kirschner teli ile geçici tespit edilir. Skopi cihazı ile uygun bulunursa distal peg deliği açılır ve ardından deneme plak çıkartılarak orijinal radyal komponent ve tüm vidalar yerleştirilir. Ardından ulnadaki rezeksiyon miktarı tam olarak değerlendirilir. Eğer daha önce geçirilmiş cerrahiye veya travmaya bağlı ulnadaki kemik kaybı fazlaysa, standart ulnar komponent yaklaşık 4 cm'ye kadar uzatılabilir. Eğer kemik kaybı daha fazla ise gerekirse kişiye özel yapım stem hazırlanabilir ancak proksimalde en az $11 \mathrm{~cm}$ kemik stoğu olmalıdır. Ardından uygun boyutta ulnar komponent yerleştirilir. Bu aşamada ulnar komponentin en distal kısmı ile radyal komponentin distal kısmı aynı seviyede olmalıdır. 
Polietilen küre ulnar komponentin distaline adapte edildikten sonra, hemi soket ve iki adet vida yardımıyla radyal komponentle birleştirilir. En son fasyal flep ile protezin üzeri örtülerek işlem tamamlanır. ${ }^{[8,10]}$

\section{Komplikasyonlar}

Ulnar osteotomi bölgesinde ektopik kalsifikasyon gelişen olgular bildirilmiştir. Tedavisinde lokal eksizyon ve bazı olgularda tek doz radyoterapi uygulanmıştır. Radyal plağın uzun olan vidalarına bağlı radyal sinir irritasyonu gelişen olgularda, uzun vidaların değiştirilmesi ile sorun giderilmiştir. Bildirilen bu komplikasyonlar dışında, EKU tendiniti ve enfeksiyon da diğer olası komplikasyonlar arasındadır. ${ }^{[10]}$

\section{SONUÇLAR}

En az bir yıl takibi olan DRUE artroplastisi yapılan hastaların; ön kol tork kuvveti, kaldırma ve kavrama güçleri ameliyat öncesinde ve sonrasında ölçülmüşs. Hastalara Herbert UHP ve Scheker total DRUE implantı kullanılmış. Ölçümler hasta ayaktayken dirsek doksan derece fleksiyonda yapılmış. Tork kuvvetinde anlamlı bir iyileşme bulunurken kavrama ve kaldırma güçlerinde değişiklik tespit edilmemiştir. [11]

Konu ile ilgili toplam 27 makaleyi değerlendirilen bir çalışmada olgu sayısı ve takip süresi yeterli bulunan 18 çalışma değerlendirilmeye alınmış. Kullanılan implantlardan ikisi ulna başı protezi iken, diğer ikisi ulna başı ile beraber sigmoid çentiği de içeren semiconstrained protezmiş. Üç çalışmada özellikle supinasyon hareketinde iyileşme tespit edilmiş. On çalışmada görsel ağrı skalası (VAS) ile ağrıda iyileşme bildirilmiş. Constrained protez uygulanan beş çalışmada kaldırma gücünde iyileşme bulunmuş. Çoğu olguda kavrama gücünde anlamlı değişiklik tespit edilmemiş. İmplant gevşemesi tespit edilen 17 çalışmanın arasında yer alan ve beş yıldan uzun süre takip süresi bildiren beş çalışmada $\% 95$ olarak bulunan sağkalım süresi (Herbert ve Mayo implant), Scheker protezinde \%98, Shuurman protezinde ise $\% 80$ olarak bulunmuş. ${ }^{12]}$

Diğer bir çalışmada; ulna rezeksiyonuna sekonder gelişen instabilitenin kavrama ve ön kol torsiyonel gücünde azalmaya sebep olduğu belirtilmiş ve bu sebeple uygulanan distal radyoulnar eklem protezlerini değerlendiren bir çalışmada; parsiyel hemiartroplasti uygulamalarının primer prosedür olarak uygulanabileceğini, rezeksiyonun minimal olması ve TFKK'nin yapışma yerinin sağlam kalması sebebiyle tercih edilebileceği, revizyon olgularında ise modüler ulna başı protezinin tercih edilebileceği belirtilmiştir. ${ }^{[3]}$

Aktif ve beklentisi yüksek hastalar; fonksiyonel, stabil ve hareketli DRU ekleme ihiyaç duyarlar. Hattâ ileri yaştaki bireyler de yemek yeme, banyo yapma ve giyinme gibi günlük işlevlerinde distal radyoulnar eklem fonksiyonlarına ihtiyaç duyarlar. Parsiyel veya total hemiartroplasti uygulamaları, sigmoid çentik karşısında DRU eklemi yeterli stabiliteyi sağlayamadığından artritik değişimlere yol açar. Bu hastaların yaklaşık yüzde otuzu on yıl içinde ek cerrahi girişimlere ihtiyaç duyarlar. Scheker, DRUE total protez uygulamalarının, bu durumların çözümünde ve önlenmesinde başarılı olduğunu düşünmektedir. ${ }^{[10]}$ Diğer taraftan Herbert, 10 yılın üzerinde takibi olan uygulamalarında hastaların ağrı durumlarındaki iyilik ve fonksiyonlarındaki iyileşmenin devam ettiğini bildirmiştir. ${ }^{[6]}$

DRUE protezlerinin, klinik olarak iyileşmeye yardımcı olsa da uzun dönem sonuçları çok iyi bilinmediği için, hasta seçimi konusunda çok dikkatli olunmalıdır. ${ }^{[13]}$

\section{KAYNAKLAR}

1. Grewal R, King GJW. Ulnar head replacement: Partial and Total (Chap. 19). In: Greenberg JA, editor. American Society for Surgery of the Hand. Ulnar - Sided Wrist Pain: A Master Skills Publication. Chicago IL: Elsevier Inc.; 2013. p. 207-12.

2. Lluch A, Garcia-Elias M. Historical Considerations (Chap. 18). In: Greenberg JA, editor. American Society for Surgery of the Hand. Ulnar - Sided Wrist Pain: A Master Skills Publication. Chicago IL: Elsevier Inc.; 2013. p.197-205.

3. Kopylov $P$, Tägil M. Distal radioulnar joint replacement. Tech Hand Up Extrem Surg 2007;11(1):109-14. Crossref

4. Garcia-Elias M. Eclypse: Partial ulnar head replacement for the isolated distal radio-ulnar joint arthrosis. Tech Hand Up Extrem Surg 2007;11(1):121-8. Crossref

5. Swanson AB. Silicone rubber implants for replacement of arthritis or destroyed joints in the hand. Surg Clin North Am 1968;48(5):1113-27. Crossref

6. Herbert TJ, van Schoonhoven J. Ulnar head replacement. Tech Hand Up Extrem Surg 2007;11(1):98-108. Crossref

7. Berger RA, Cooney 3rd WP. Use of an ulnar head endoprosthesis for treatment of unstable distal ulnar resection: review of mechanics, indications and surgical technique. Hand Clin 2005;21(4):603-20. Crossref

8. Scheker LR, Oron A. Total DRUJ Replacement (Chap. 20). In: Greenberg JA, editor. American Society for Surgery of the Hand. Ulnar - Sided Wrist Pain: A Master Skills Publication. Chicago IL: Elsevier Inc.; 2013. p.213-20.

9. Schuurman $\mathrm{AH}$, Teunis $\mathrm{T}$. A new total distal radioulnar joint prosthesis: functional outcome. J Hand Surg Am 2010;35(10):1614-19. Crossref

10. Scheker LR. Implant arthroplasty for the distal radioulnar joint. J Hand Surg Am 2008;33(9):1639-44. Crossref

11. Axelsson $\mathrm{P}$, Sollerman $\mathrm{C}$, Kärrholm J. Validity and responsiveness of forearm strength measurements in the evaluation of distal radioulnar joint implant arthroplasty. J Hand Surg Am 2020;45(8):778.e1-7. Crossref

12. Calcagni M, Giesen $T$. Distal radioulnar joint arthroplasty with implants: a systematic review. EFORT Open Rev 2017;13;1(5):191-6. Crossref

13. Cooney 3rd WP, Berger RA. Distal radioulnar joint implant arthroplasty. J Hand Surg Am 2005;5(4):217-31. Crossref 